\title{
La arteria cultural del cuerpo estatal: el campo de las Bellas Artes en la construcción del Estado liberal español (1833-1874)
}

Ainhoa Gilarranz Ibáñez

Universidad Sorbonna Nouvelle-París 3

gilarranz.ainhoa@gmail.com

Fecha recepción 19.03.2018 / Fecha aceptación 23.04.2018

\section{Resumen}

A partir de la década de los 90, un conjunto de historiadores reabrió el debate sobre la construcción del estado-nación con miradas que fluctuaban entre una estructura fuerte o débil de los estados europeos. El giro cultural en la historia contemporánea introdujo nuevos puntos de vista que podrían resumirse en un estudio «desde abajo» de la construcción estatal, en el que los imaginarios, las identidades y el individuo eran el principal corpus analítico. Continuando con esta línea, las siguientes páginas profundizan en las posibilidades que la mirada cultural ofrece en el estudio de un proceso histórico tan complejo. En concreto, cómo observar el campo artístico, fraccionado en sus instituciones, universos simbólicos y agentes, se podrían iluminar algunas de las sombras de la construcción del Estado-nación decimonónico.

\section{Palabras clave}

Estado liberal, siglo XIX, historia cultural, arte.

\section{Abstract}

In the 1990s, a group of historians reopened the debate on the building of nation states. Perspectives swung between a strong or a weak structure for European states. This cultural wave in contemporary history introduced new viewpoints that can now be summarised in a «bottom up» analysis of state building. Continuing with this line of thought, this work explores the possibilities opened up by adopting a cultural perspective of such a complex historical process. Specifically, how observing the artistic field, with its lines dividing institutions, symbolic universes and agents, could shed new light on nineteenth-century nation-state building.

\section{Keywords}

Keywords: liberal State, 19th century, Cultural history, art. 

EN LA DÉCADA DE LOS 90 SE REABRIó UN INTENSO DEBATE entre los investigadores dedicados a la historia de la nación y de la nacionalización. Borja de Riquer continuó con la línea de análisis del sociólogo Juan José Linz ${ }^{1}$, y puso sobre la mesa las problemáticas que envolvían los estudios de la construcción nacional en la historiografía contemporánea española ${ }^{2}$. Desde entonces, la identidad nacional y el nacionalismo español han sido objeto de discusión constante. En líneas generales, esos trabajos publicados concluyeron que el Estado liberal había sido demasiado débil para penetrar en la sociedad española ${ }^{3}$. El relato postulaba la inefectividad de las instituciones estatales a la hora de nacionalizar el país; los argumentos se centraban en la fragilidad económica y social del aparato estatal y su necesidad de negociar con los poderes regionales y locales ${ }^{4}$.

El consenso sobre la débil nacionalización española duró poco. La renovación historiográfica puso rápidamente en evidencia algunos aspectos del relato dominante ${ }^{5}$; al mismo

1. J. J. Linz, "Early State-Building and Late Peripheral Nationalism against the State", en S. Rokkan y S. N. Eisenstadt (eds.), Building States and Nations, Londres, 1972, 32-112; J. J. LINZ: "Los nacionalismos en España: una perspectiva comparada”, en J. Casassas y E. D’Auria (coords.), El Estado Moderno en Italia y España: ponencias del Simposio Internacional "Organización del Estado moderno y contemporáneo en Italia y España", Barcelona, 1993, 79-88.

2. F. Molina y M. Cabo Villaverde, "An Incovenient Nation: Nation-Building and National Identity in Moderns Spain. The Historiographical Debate”, en M. V. Ginderachter y M. Beyen (eds.): Nationhood from below. Europe in the long nineteenth century, Londres, 2012, 47-72.

3. B. de Riquer, "Reflexiones en torno a la débil nacionalización española del siglo XIX”, LAvenç, 170, 1993, 8-15; ID., "Aproximación al nacionalismo español contemporáneo", Studia histórica. Historia contemporánea, 12, 1994, 11-29; ÍD., "Nacionalidades y regiones. Problemas y líneas de investigación en torno a la débil nacionalización española del siglo XIX”, en M. E. de Vega y A. Morales Moya (coords.), La historia contemporánea en España: primero Congreso de Historia Contemporánea en España, Salamanca, 1996, 73-92.

4. G. Martínez Dorado, "La formación del Estado y la acción colectiva en España: 1808-1845, Historia Social, 15, 1993, 101-118; J. P. Fusi, “Centralismo y localismo: la formación del Estado español”, en G. Gortázar (coord.), Nación y estado en la España liberal, Madrid, 1994, 77-90; J. Álvarez Junco, "La nación en duda”, en J. Pan-Montojo (coord.): Más se perdió en Cuba: España, 1898 y la crisis de fin de siglo, Madrid, 1998, 405476; ÍD.: Mater Dolorosa: la idea de España en el siglo XIX, Madrid, 2001.

5. M. Martí y F. Archilés: "La construcción de la Nación española durante el siglo XIX”, Ayer, 35, 1999, 171-190; F. Archilés, “¿Quién necesita la nación débil?: la débil nacionalización española y los historiadores”, en A. Sabio Alcutén, R. Valls Montés, C. Forcadell, I. Peiró y G. V. Pasamar (coords.), Usos de la historia y 
tiempo que se abrían nuevas vías de investigación sobre la construcción del Estado, abordado desde diversas perspectivas como la historia jurídica, económica o administrativa ${ }^{6}$. Sin embargo, como bien indicaba Xosé Núñez Seixas, ninguna de estas posturas se aproximaba al impacto social ${ }^{7}$. Fue así como la historia cultural se aproximó a la construcción de los estados-nación mediante el estudio de las identidades sociales, los imaginarios y los símbolos nacionales ${ }^{8}$. El giro cultural en la historia contemporánea propició el análisis de las representaciones -políticas, sociales, culturales- y su papel en la construcción cultural de la nación. «Hemos sentimentalizado el Estado llamándolo nación», aseguraba Juan Sisinio Pérez', lo que provocó una marginación de los procesos y prácticas propias del Estado que quedaron relegadas historiográficamente al ámbito administrativo, institucional o burocrático ${ }^{10}$; al mismo tiempo que las prácticas colectivas y las identidades se atribuían al ámbito de la construcción nacional ${ }^{11}$. No obstante, estos mismos trabajos estimularon un debate sobre el papel del Estado en su propia definición. Los investigadores se fueron alejando del concepto clásico que entendía el aparato estatal como instrumento de la clase dominante, para contemplarlo como un conjunto de prácticas políticas negociadas socialmente desde diversas organizaciones $^{12}$. El concepto de Estado no estaba predeterminado, su creación se debía al impacto de diversas ideologías, colectivos, grupos sociales que fueron dándole forma ${ }^{13}$.

La aproximación cultural a la historia política fomentó la percepción del Estado-nación como un organismo capaz de construir valores cívicos, culturales y con el que representar un

políticas de la memoria, Zaragoza, 2004, 187-208; F. Archilés y M. García Carrión, "En la sombra del Estado: esfera pública nacional y homogeneización cultural en la España de la Restauración”, Historia contemporánea, 45, 2012, 483-518.

6. M. Artola, La Hacienda del siglo XIX: progresistas y moderados, Madrid, Alianza Editorial, 1986; E. García de Enterría, La administración española: estudios de ciencia administrativa, Madrid, 1961; J. Varela Suanzes-Carpegna, La teoría del Estado en los orígenes del constitucionalismo hispánico, Madrid, 1983.

7. X. M. Núñez Seixas, "Los oasis en el desierto. Perspectivas historiográficas sobre el nacionalismo español", Bulletin d'Histoire Contemporaine de l'Espagne, 26, 1997, 483-533.

8. S. Calatayud, J. Millán y M. C. Romeo, "El Estado en la configuración de la España contemporánea. Una revisión de los problemas historiográficos”, en S. Calatayud, J. Millán y M. C. Romeo (coords.), Estado y periferias en la España del siglo XIX, Valencia, 9-130.

9. J. Sisinio Pérez, "El nacionalismo español en sus orígenes: factores de configuración”, Ayer, 35, 1999, 53-86.

10. J. Pro, "La construcción del Estado en España: haciendo historia cultural de lo político", Almanack, 13, 2016, 1-30.

11. J. Álvarez Junco, “El nacionalismo español como mito movilizador. Cuatro guerras”, en M. Pérez Ledesma y R. Cruz Martínez (coord.), Cultura y movilización en la España contemporánea, Madrid, 1997, 35-67; P. B. Radcliff, "La representación de la nación. El conflicto en torno a la identidad nacional y a las prácticas simbólicas en la Segunda República”, en M. Pérez Ledesma y R. Cruz Martínez (coord.), Cultura y movilización en la España contemporánea, Madrid, 1997, 305-325.

12. R. Cruz Martínez, "El más frío de los monstruos fríos: la formación del Estado en la España contemporánea”, Política y sociedad, 18, 1995, 81-92.

13. J. Pan-Montojo y J. Pro, “Presentación. Culturas de Estado en la Península Ibérica”, Historia y política: Ideas, procesos y movimientos sociales, 36, 2016, 13-18. 
foco de identidad ${ }^{14}$. Al fin y al cabo, el órgano estatal poseía un poder cedido y para mantenerlo necesitaba legitimarse. ¿Cómo? A partir de estrategias culturales, universos simbólicos con los que los gobernados interiorizasen el constructo estatal y lo naturalizaran ${ }^{15}$. En Sobre el Estado. Cursos en el Collége de France (1898-1992), Pierre Bourdieu reflexionaba sobre las herramientas simbólicas con las que los Estados controlaban a los ciudadanos. El sociólogo francés consideraba al Estado como un metacampo cuyo objetivo era hacerse con el monopolio del resto de campos originarios de la fragmentación social. Para conseguir ese control, necesitaba hacerse con el dominio tanto de la violencia física como de la simbólica y, por lo tanto, requería de un capital simbólico para ejercer su poder ${ }^{16}$.

La renovación historiográfica de la historia política derivó en el estudio de las culturas políticas. Dentro de sus análisis surgió la noción de la cultura de Estado entendida como el imaginario compartido por un grupo sobre lo que debería ser y lo que es el Estado a partir de un universo simbólico: ritos, lenguajes, discursos narrativos, signos, etc ${ }^{17}$. Este concepto fue ampliamente desarrollado en el proyecto de investigación Imaginarios de Estado: modelos, utopías y distopías en la construcción del Estado-nación español en perspectiva comparada (siglos XVII-XIX) ${ }^{18}$. Dentro de los trabajos enmarcados en este proyecto, la cultura de Estado ha servido de hilo conductor para conocer la construcción estatal desde las ideologías políticas, los grupos sociales y también los cuerpos administrativos o de funcionariado ${ }^{19}$. Una contribución analítica ha sido ampliada en una reciente monografía titulada: El Estado desde la sociedad. Espacios de poder en la España del siglo XIX, que a su vez profundiza en áreas anunciadas años antes en Estados y periferias en la España del siglo XIX. Nuevos enfoques. Se trata de un conjunto de estudios dedicados a la formación del Estado «desde abajo» con los que se intenta comprender la construcción y las «influencias mutuas» entre la sociedad y el órgano estatal $^{20}$. En esencia, desde esta nueva perspectiva, el análisis lineal de la construcción estatal desaparece para abrir camino al reconocimiento de una realidad compleja de este proceso

14. M. Keating, "Naciones, nacionalismos y Estados", Revista internacional de filosofía política, 3, 1994, 39-59.

15. J. Pro, "La construcción del Estado en España...”, op. cit., 2-3.

16. P. Bourdieu, Sobre el Estado: cursos en el Collège de France (1989-1992), Barcelona, 2014.

17. J. Pan-Montojo y J. Pro, “Presentación. Culturas de Estado...”, op. cit., 14.

18. Proyecto HAR2012-32713 de la Dirección General de Investigación Científica y Técnica (MINECO), dirigido por Juan Pro Ruíz entre 2013 y 2015.

19. D. Martykánová, "Remover los obstáculos. Los ingenieros de caminos españoles y sus visiones del Estado durante la segunda mitad del siglo XIX”, Historia y política: Ideas, procesos y movimientos sociales, 36, 2016, 49-73; J. Pan-Montojo, "El Estado según los altos funcionarios de la Hacienda Española: 1881-1936", Historia y política: Ideas, procesos y movimientos sociales, 36, 2016, 75-101; J. Pro, "El Estado grande de los moderados en la España del siglo XIX”, Historia y política: Ideas, procesos y movimientos sociales, 36, 2016, 19-58; M. Artola Blanco, "Los años sin rey: imaginarios aristocráticos durante la Segunda República y el primer franquismo (1931-1950), Historia y política: Ideas, procesos y movimientos sociales, 36 (2016), 103-127.

20. S. Calatayud, J. Millán y M. C. Romeo, "Introducción: la formación del Estado "desde abajo". Poder, sociedad y conflictos en la España del siglo XIX” en S. Calatayud, J. Millán y M. C. Romeo (coord.), El estado desde la sociedad: espacios de poder en la España del siglo XIX, Alicante, 2016, 9-37. 
histórico que pasa a ser considerado una construcción interdependiente entre el discurso y la práctica ${ }^{21}$. Se trata de una interacción en ambos sentidos: hay que ser conscientes tanto de las acciones y mensajes nacionalizadores — provenientes de la Administración, la enseñanza, los partidos políticos, la prensa, y un sinfín de agentes sociales - como de las diversas recepciones y respuestas sobre esos discursos ${ }^{22}$.

\section{Los retos de la historia cultural del Estado: el escenario de las Bellas Artes}

La crisis de penetración del Estado en el entramado social del liberalismo, como así lo describía José Álvarez Junco ${ }^{23}$, se ha consolidado con estudios de conclusiones heterogéneas; mientras que algunos autores apelaban a su debilidad de actuación, otros aseguraban que su ineficacia vino dada por una normativa impuesta que no se ajustaba a la población, ocasionando más dificultades a la población que ayudas ${ }^{24}$. En este último aspecto, son muy interesantes los estudios dedicados al control urbano por parte de los estados, desde los espacios de vigilancia como las cárceles, hasta la toma de decisiones en la planimetría urbana de las ciudades ${ }^{25}$. No obstante, la división de paradigmas sobre el carácter del Estado español, etiquetado como fuerte o débil, no satisface a todos los investigadores al no tener en cuenta ni el tiempo histórico, ni el amplio abanico de espacios en los que actúa el Estado ${ }^{26}$. En las siguientes líneas, pongo sobre la mesa cómo desde el análisis de la nacionalización se ha reflexionado sobre la construcción del Estado decimonónico. Seguidamente, identificaré las lagunas que en este sentido quedan por rellenar y los posibles caminos que la historia cultural de la política ofrece para el estudio de la construcción estatal.

Desde el giro cultural en la historia contemporánea, los procesos de nacionalización se han estudiado desde áreas artísticas como la literatura, el teatro, la ópera o la zarzuela. Sería imposible anotar todas las investigaciones realizadas en este ámbito, especialmente en el campo literario ${ }^{27}$; no obstante, hay estudios recientes que deben destacarse como $E l$

21. W. Reinhard, Las élites del poder y la construcción del Estado, Madrid, Fondo de Cultura Económica de España, 1997.

22. J. Beramendi y A. Rivera, “La nacionalización española: cuestiones de teoría y método”, en F. Luengo Teixidor y F. Molina Aparicio (eds.), Los caminos de la nación. Factores de nacionalización en la España contemporánea, Granada, 2016, 3-32.

23. J. Álvarez Junco, Mater Dolorosa... op. cit., 533-627.

24. J. Álvarez Junco, Mater Dolorosa... op. cit., 540-544; R. Cruz Martínez, “El más frío de los monstruos fríos... op. cit., 85-86.

25. R. Chartier, Espacio público, critica y desacralización en el siglo XVIII. Los orígenes culturales de la Revolución francesa, Barcelona, 1995; H. Lefevbre, La producción del espacio, Madrid, 2013; M. Delgado, El espacio público como ideología, Madrid, 2011. Q. Bonastra y V. Casals (eds.), Espacios de control y regulación social: ciudad, territorio y poder (siglos XVII-XX), Barcelona, 2014.

26. R. Cruz Martínez, "El más frío de los monstruos fríos... op. cit., 84.

27. J. Canal, “Hijos de la España del siglo XIX: Benito Pérez Galdós, los “Episodios nacionales”, y el patriotismo", en A. Morales, J. P. Fusi y A. Blas (coord.), Historia de la nación y del nacionalismo español, Barcelona, 2013, 307-321; E. Inman Fox, "La invención de España: literatura y nacionalismo”, en D. Flitter (coord.), 
descubrimiento de España. Mito romántico e identidad nacional, obra en la que se examina la creación del imaginario español desde el análisis de diversas fuentes literarias. Sus referencias añaden a las figuras reconocidas -como José Zorilla al que le dedica varios apartados- otras obras de autores menos canonizados ${ }^{28}$. Muchos de los mitos e ideas reproducidas en la literatura también se vieron reflejadas en el discurso teatral y musical. Tanto el teatro como la ópera nacional difundieron imaginarios de la nación al que los investigadores se han aproximado en la última década desde dos líneas definidas: el análisis de sus discursos ${ }^{29}$ y como escenario de sociabilidad ${ }^{30}$.

Como han indicado muchos estudios anteriormente citados, la construcción de los estados es un proceso dinámico, cambiante en función del tiempo histórico. Por ello, las siguientes reflexiones están acotadas a las posibilidades analíticas que el mundo artístico, concretamente el de las Bellas Artes españolas puede ofrecer en el campo de la creación del Estado liberal del siglo XIX. Este recorrido se realizará por tres caminos principales: las instituciones, el universo simbólico y los agentes sociales.

\section{Instituciones}

La configuración del Estado, como organismo institucional y administrador de los poderes políticos, se ha contemplado como un proceso iniciado en el siglo XVIII. Se considera que fue entonces cuando las monarquías absolutistas ilustradas trataron de centralizar su poder y fortalecer su posición a través de una red de control con la que se construyó el primer cuerpo

Actas del XIII Congreso de la Asociación Internacional de Hispanistas, vol. 4 (Del Romanticismo a la Guerra Civil), University of Birmingham, 1998, 1-16.

28. X. Andreu Miralles, El descubrimiento de España: mito romántico e identidad nacional, Barcelona, 2016.

29. J. C. Ferrera, “PPatriotismo o degradación de la nación?: el teatro bufo de Arderius (1866-1872)”, en P. Folguera, J. C. Pereira, C. García, J. Izquierdo, R. Pallol, R. Sánchez, C. Sanz y P. Toboso (coord.), Pensar con la historia desde el siglo XXI: actas del XII Congreso de la Asociación de Historia Contemporánea, Madrid, 2015, 4025-4043; F. J. Rosal Nadales, “"Patria» y «nación» en la cultura española contemporánea y su presencia en las zarzuelas sobre la Guerra de la Independencia (1847-1931)", Espacio Tiempo y Forma, 27, 2015, 227-246; E. Asensi, «En busca de una “ópera nacional”: la música en la construcción de identidades en la España contemporánea», en M. E. Nicolás y C. González (coords.), Ayeres en discusión: temas clave de Historia Contemporánea hoy, Murcia, 2008, s. p.; E. Casares, «El libreto en la construcción de la ópera nacional», en M. Espín Templado (coord.), Teatro lírico español: ópera, drama lírico y zarzuela grande entre 1868 y 1925, Madrid, 2017, 13-56.

30. A. Romero, "La escenografía teatral de la sociabilidad popular: cafés, patios de vecinos, tabernas, ferias y verbenas (del sainete a la zarzuela)", en Casinos, tabernas, burdeles: ámbito de sociabilidad en torno a la ilustración, Córdoba, 2017, 79-104; S. Slaün, "La sociabilidad en el teatro (1890-1915)", Historia social, 41, 2001, 127-146J. Piñeiro, «El teatro de ópera como centro de articulación social y cultural en España durante el siglo XIX: Madrid y Barcelona», en M. E. Nicolás y C. González (coords.), Ayeres en discusión: temas clave de Historia Contemporánea hoy, Murcia, 2008, s.p.

Revista de historiografía 30, 2019, pp. 245-262 
estata $^{31}$. Con la llegada del liberalismo, la Constitución fue la normativa que dio forma a las instituciones estatales. Su contenido versaba sobre los derechos de los individuos, la división de poderes, y las labores de la administración del Estado en todas sus ramas: hacienda pública, ejército, educación; y es que, en esencia, el órgano estatal se conformaba por un conjunto de instituciones dotadas de poder, de una autoridad que le había cedido la nación ${ }^{32}$. A la hora de indagar en la construcción del Estado una de las principales áreas de estudio ha sido aproximarse a la formación de sus instituciones. Hay numerosas monografías dedicadas al origen y evolución de la Administración, a su división ministerial, a los diversos organismos que lo conforman ${ }^{33}$. Sin embargo, hasta fechas relativamente recientes el análisis de la configuración institucional del Estado no se ha vinculado a su trascendencia social, es decir, cómo las instituciones y sus prácticas inciden en la conformación y desarrollo de grupos sociales ${ }^{34}$. La hipótesis sobre la debilidad del Estado liberal se asienta en la incapacidad de las instituciones por promover un ideario nacional; una labor que, según señalan los partidarios de esta hipótesis, quedó en manos privadas o semiprivadas ${ }^{35}$. El campo educativo ha sido de los más examinados en esta perspectiva. En 1857 se puso en marcha la reforma de la educación a partir de la Ley Moyano, una legislación que organizaba un sistema educativo a nivel nacional desde la enseñanza obligatoria hasta el doctorado. Pese a su ambición, los gastos de dicho plan no podían ser sufragados por el Estado. Esta carencia de recursos dio lugar a que casi dos tercios de la población fuese aún analfabeta a finales del siglo XIX ${ }^{36}$. El fracaso del sistema educativo se percibió como una vía menos para consolidar una identidad nacional desde la historiografía de los años $90^{37}$. A finales de esa década, en oposición a estas percepciones, desde la historia social y cultural se rebatieron estas hipótesis con el estudio de otras prácticas educativas como la lectura en voz alta y el estudio de los programas escolares en los que se

31. S. Rus Rufino (coord..), La razón de Estado en la España Moderna, Valencia, 2000; I. Enciso AlonsoMuñumer (coord..), Carlos III y su época: la monarquía ilustrada, Barcelona, 2003.

32. J. M. Portillo Valdés, "Estado”, en J. Fernández Sebastián y J. Francisco Fuentes (dirs.), Diccionario político y social del siglo XIX español, Madrid, 2002, 295-302.

33. La formación de las diputaciones es uno de los temas destacados por la historiografía contemporánea, entre los últimos trabajos véase: A. de Anta, La Diputación Provincial de Valladolid en el siglo XIX (1813-1874): el puente entre el estado liberal y los ayuntamientos, Valladolid, 2014; F. J. Cuerva, El gobierno provisional en los inicios del estado liberal (1833-1843): subdelegados de fomento, gobernadores civiles y jefes políticos. Estudio de caso en la provincia de Sevilla, Valencia, 2014. También encontramos trabajos dedicados a instituciones estatales: P. Tedde de Lorca, El Banco de España y el Estado liberal (1847-1874), Madrid, 2015.

34. Junto con el sistema educativo, la sanidad y la beneficencia han sido de las áreas más trabajadas en este aspecto: E. Maza Zorrilla, Pobreza y beneficencia en la España contemporánea (1808-1936), Barcelona, 1999; A. Cardona, La salud pública en España durante el Trienio Liberal (1820-1823), Madrid, 2005; R. Huertas, Los laboratorios de la norma: medicina y regulación social en el Estado liberal, Barcelona, 2008.

35. J. Álvarez Junco, “La nación en duda...”, op. cit., 445; ID, Mater Dolorosa... op. cit., 187-281.

36. M. Villanova y X. Moreno, Atlas de la evolución del analfabetismo en España. De 1887 a 1981, Madrid, 1992.

37. M. de Puelles Benítez, Estado y educación en la España liberal (1809-1857): un sistema educativo frustrado, Barcelona, 2004. 
encontraban áreas de conocimiento dedicadas al «Gobierno, religión e idioma de España» o a la geografía de «la Nación». De este modo, el alto analfabetismo social no equivalía a una ausencia de nacionalización ya que el aprendizaje podía venir de maneras no regladas ${ }^{38}$.

Estas nuevas miradas ofrecían un análisis de prácticas de nacionalización no institucionalizadas. No obstante, este protagonismo en el debate de las escuelas e institutos públicos ha dejado en la sombra el estudio de otras áreas desde donde la Administración también podía desarrollar una labor pedagógica: las instituciones culturales. Por poner algunos ejemplos: desde 1833, cuando se estableció la división territorial de Francisco Javier de Burgos, se creó un subdelegado de Fomento dedicado a las bibliotecas, museos y al perfeccionamiento de estos establecimientos. A raíz de esta primera administración se fue consolidando la sección de Bellas Artes dentro de la Instrucción Pública del Estado ${ }^{39}$. Esta se hacía cargo de los establecimientos culturales de la nación: diálogo con las academias de Bellas Artes, control de colecciones museísticas, propuesta de proyectos monumentales, etc. A mediados del siglo XIX, los debates entorno al patrimonio nacional desembocaron en la creación de las comisiones de monumentos históricos y artísticos coordinadas desde el Ministerio de Fomento, se impulsó la creación del edificio de Bibliotecas y Museos nacionales, y se crearon las Exposiciones Nacionales a través de las que se configuró una colección pictórica estatal. La creación de cada una de estas instituciones es una muestra de las interconexiones del mundo artístico con el organismo estatal del siglo XIX. Pero ¿Cómo se han influido mutuamente? El estudio de estas instituciones culturales se ha desarrollado desde tres vías: administrativa, museológica y patrimonial. Cada uno de estos caminos ha profundizado en aspectos mencionados anteriormente como la identidad nacional y la creación de espacios de sociabilidad; sin embargo, sus relaciones con el Estado han sido brevemente abordadas.

En el caso de las academias de Bellas Artes, vinculadas administrativamente desde la Ley Moyano de 1857, se han analizado sus peculiaridades regionales, los artistas que formaron parte de ellas y los debates artísticos surgidos en su seno ${ }^{40}$. No obstante, queda por conocer las relaciones, enfrentamientos o colaboraciones con la administración estatal ${ }^{41}$. Al-

38. M. Martí y F. Archilés, "La construcción de la Nación española durante el siglo XIX...”, op. cit., 176177; F. Archilés, "Vivir la comunidad imaginada. Nacionalismo español e identidades en la España de la Restauración”, Historia de la educación. Revista interuniversitaria, 27, 2008, 57-85.

39. J. García Fernández, "Inicios de la organización administrativa de las bellas artes (1803-1868)", en VV. AA., Cien años de administración de las Bellas Artes, Madrid, 55-78.

40. C. Reyero, Pintores españoles del siglo XIX en la Escuela de Bellas Artes de París: entre el aprendizaje cosmopolita y el mérito curricular, Madrid, 1991; E. Navarrete Martínez, La enseñanza de la pintura y los pintores en la Real Academia de Bellas Artes de San Fernando de Madrid durante la primera mitad del siglo XIX, Madrid, 1999; C. Rodríguez Samaniego, "La educación artística en la Escuela de Bellas Artes de Barcelona durante el siglo XIX. El caso de la escultura”, Arte, individuo y sociedad, 25, 2013, 495-508; E. Povedano, "Paisaje y Academia: las enseñanzas artísticas entre siglos", Arte y Ciudad: revista de investigación, 3, 2013, 403-424.

41. La investigación sobre el coleccionismo y el mecenazgo ha aproximado a los historiadores a los espacios académicos como escenarios de institucionalización artística: M. D. Jiménez-Blanco, Arte y estado en la España del siglo XX, Madrid, 1989; I. Henares Cuéllar (coord.), Campo artístico y sociedad en España 
gunos avances se han dado en relación con la creación la comisión central y de las comisiones provinciales de monumentos históricos y artísticos y su papel en la creación de museos provinciales $^{42}$. Sin embargo, estos trabajos, que plantean debates patrimoniales y artísticos, dejan al margen las relaciones establecidas entre agentes sociales y políticos y no abordan la interacción con el aparato del Estado.

Por otra parte, la historia de los museos en España se ha centrado principalmente en su creación por parte de las élites y en la evolución de sus colecciones, en donde el Museo del Prado ha sido el gran protagonista del periodo decimonónico ${ }^{43}$; aunque, por suerte, gracias al impulso renovador en la museología española de Pierre Gèal, los estudios más recientes presentan los espacios museísticos como escenarios en donde la esfera artística y el poder político dialogan ${ }^{44}$. Una perspectiva abordada desde la escuela francesa y especialmente en los estudios de Dominique Poulot, en los que el análisis del patrimonio y la nación se han entrecruzado con la acción del Estado republicano surgido en $1789^{45}$. Centrándome en el caso español, se aportarían muchos datos sobre los vínculos entre el poder oficial y el mundo artístico si se aproximase la mirada al Museo Nacional de la Trinidad, creado a partir de las desamortizaciones de Mendizábal, o a los museos provinciales desde la perspectiva de la sociabilidad formal: conocer sus relaciones con otras instituciones culturales, profundizar en sus figuras directivas y en la creación de redes intelectuales. En definitiva, trasladar el análisis que se ha realizado en espacios como los ateneos o liceos a un escenario como el museístico ${ }^{46}$.

(1836-1936): la institucionalización del arte y sus modelos, Granada, 2016; I. Socias Batet (coord.), Nuevas contribuciones en torno al mundo del coleccionismo de arte hispánico en los siglos XIX y XX, Gijón, 2013.

42. E. Alba Pagán, "La génesis del Museo de Bellas Artes de Valencia y la polémica en torno a los bienes desamortizados a través de la prensa valenciana", en F. J. Campos (coord.), La desamortización: el expolio del patrimonio artístico y cultural de la Iglesia en España, Madrid, 2007; I. Arana Cobos, "Las comisiones artísticas tras la desamortización de Mendizábal y la formación de los museos provinciales: la labor de Valentín Carderera", Argensola: revista de Ciencias Sociales del Instituto de Estudios Altoaragoneses, 120, 2010, 15-33; M. T. Chávarri Caro, La Real Academia de Bellas Artes de San Fernando y la protección del patrimonio desamortizado, Tesis doctoral, Madrid, 2013.

43. M. Bolaños, Historia de los museos en España: memoria, cultura, sociedad, Gijón, 1997; S. Reuben Holo, Beyond the Prado: museums and identity in democratic Spain, Washington, 1999; J. A. Gaya Nuño, Historia y guía de los museos de España, Madrid, 1955; A. Colorado, El Museo del Prado en sus 175 años de historia, Madrid, 1996; ÍD, Éxodo y exilio del arte: la odisea del Museo del Prado durante la Guerra Civil, Madrid, 2008.

44. P. Géal, "Recherches sur la naissance des musées d’art en Espagne de Charles III à Isabelle II", Bulletin d'histoire contemporaine de l'Espagne, 27, 1998, 199-204; ÍD, "La creación de los museos en España", Anuario del Departamento de Historia y Teoría del Arte, 37, 2001, 289-298; ID, La naissance des musées d'art en Espagne (XVIIIE-XIXE siècles), Madrid, 2005.

45. D. Poulot, De l'héritage monumental á l'entreprise de patrimoine: pour une histoire de la transmission culturelle en France, XVIIIe-XXe, Florencia, 1991; ÍD, Le public, l'Etat et l'artiste: essai sur la politique de musée en France des Lumières à la Révolution, Florencia, 1992; ÍD, Museo y museología, Madrid, 2011.

46. Trasladar la metodología utilizada en los estudios sobre sociabilidad en escenarios culturales podría ayudar al respecto: J. A. Martínez Martín (coord.), Orígenes culturales de la sociedad liberal: España siglo XIX, Madrid, 2003. 


\section{Universos simbólicos}

El giro cultural dio la vuelta a los estudios de los nacionalismos: junto al análisis de las ideologías políticas, los estudios se aproximaron a la dimensión cultural de sus prácticas, símbolos y representaciones. Según esta nueva perspectiva, lo interesante del nacionalismo era la experiencia social que se generaba a su alrededor, es decir, la interiorización o no de su discurso entre la sociedad. De este modo, comenzaron a proliferar las investigaciones que ahondaban en la construcción de culturas nacionales y de los universos simbólicos con los que los ciudadanos se adhieren a esa identidad nacional. Estos estudios se centraban en el análisis de las «experiencias de la nación» y del proceso comunicativo de la nacionalización. En ellas, el concepto de nación se comprende como una narración formada de metáforas e imágenes reproducidas discursivamente ${ }^{47}$.

Las renovaciones analíticas de Maurice Agulhon, aproximándose al estudio de las alegorías nacionales de Francia, y de Pierre Nora con sus investigaciones sobre los lugares de la memoria dieron un impulso al análisis de los lenguajes simbólicos. Ambos autores revitalizaron la historia cultural de la política y acercaron los universos simbólicos a esta corriente historiográfica ${ }^{48}$. En el caso español, el análisis de la alegoría nacional ha tenido un amplio recorrido con figuras destacadas como Marie-Ángele Orobon o Carlos Reyero ${ }^{49}$. Ambos autores han revalorizado la fuente iconográfica en la historia contemporánea y a través de profundizar en el lenguaje icónico y su utilización en los espacios de sociabilidad de las diversas culturas políticas, han ofrecido otras perspectivas en el estudio de la identidad nacional.

En cuanto al Estado, sus gobernantes utilizan imágenes de la nación para representarlo. Se configura una cultura formada de elementos tangibles e intangibles para personificar al Estado ante la ciudadanía, desde la construcción de una red de caminos, museos, hospitales, colegios, etc., hasta la configuración de una historia nacional llena de mitos, héroes que se difunden a través de las artes - literatura, pintura, escultura- o las festividades ${ }^{50}$. Esta «cultura legítima» ofrecida desde el Estado, no se construye ni consolida de un día para otro, sus

47. Entre los últimos trabajos presentados sobre ello: F. Archilés, "Lenguajes de nación. Las "experiencias de nación” y los procesos de nacionalización: propuestas para un debate”, Ayer, 90, 2013, 91-114; A. Quiroga, "La nacionalización en España. Una propuesta teórica", Ayer, 90, 2013, 17-38.

48. M. Agulhon, Marianne au combat: l'imagerie et la symbolique republicaines de 1789 a 1880, París, 1979; ÍD, Política, imágenes, sociabilidades: de 1789 a 1989, Zaragoza, 2016; P. Nora (ed.), Les lieux de mémoire: La Repúblique, París, 1984.

49. M. A. Orobon, "El cuerpo de la nación: alegorías y símbolos políticos en la España liberal (18081874), Feminismo/s, 16, 2010, 39-64; ID, “Marianne y España: la identidad nacional en la Primera República española”, Historia y política: Ideas, procesos y movimientos sociales, 13, 2005, 79-98; ID, "La religión de la liberté: symboles et allégories dans l'imagerie libérale de l'espagne du XIXe siècle”, Pandora: revue d'etudes hispaniques, 4, 2004, 173-188; C. Reyero, Alegoría, nación y libertad: el Olimpo constitucional de 1812, Madrid, 2010; ID, ,Monarquía y romanticismo: el hechizo de la imagen regia, 1829-1873; Madrid, 2015.

50. X. Andreu Miralles, El descubrimiento de España. Mito romántico e identidad nacional, Barcelona, 2016; P. Gabriel y T. Pérez Vejo, "Iconografías y representación de la nación”, en F. Luengo y F. Molina (coord.), Los caminos de la nación. Factores de nacionalización en la España contemporánea, Granada, 2016, 33-52; C. Reyero, "Monumentalizar la capital: la escultura conmemorativa en Madrid durante el siglo XIX", 
signos pueden ser aceptados, rechazados o reutilizados ${ }^{51}$. De ahí, la importancia de analizar el proceso comunicativo al completo, no sólo una de las partes.

Entre los estudios de la dimensión cultural del nacionalismo, han sido los dedicados al mensaje -la narrativa de la nación en palabras de Alejandro Quiroga- los que más impulso han tomado desde la historia cultural de la política, y dentro de ellos, el himno y la bandera han sido protagonistas ${ }^{52}$. La diversidad política en la España decimonónica, con enfrentamientos constantes dentro del propio liberalismo y, a su vez, este con las posturas absolutistas, apareció en el terreno de las batallas simbólicas, que a su vez afectaron en la falta de un consenso para su oficialización. Todo ello, ha sido percibido desde la historiografía contemporánea como otro factor de la debilidad del Estado-nación. No obstante, quedan lagunas por llenar con las que se podría ofrecer una alternativa a este pensamiento. Centrémonos en las fuentes visuales como herramientas de difusión de una identidad nacional; una de las más analizadas ha sido la pintura de historia, género especialmente solicitado por las instituciones estatales en el siglo XIX. El Estado constituyó la fuente de ingreso de muchos pintores españoles; a cambio, lo que las instituciones demandaban eran cuadros de temática histórica con los que crear un discurso nacional. En un periodo de crisis política y económica, el inmenso gasto de la administración en la compra de obras artísticas no debe considerarse como una anécdota, y es por ello que, en su último trabajo, Tomás Pérez Vejo cuestionaba el supuesto fracaso del Estado liberal en su acción nacionalizadora. Como bien indicaba: «en todo caso, si es que tenemos que hablar de fracaso, no sería tanto en la creación de una imagen nacional, sino en su difusión ${ }^{53}$. Profundizar en el proceso comunicativo y ampliar el abanico de fuentes, así como aproximarse a otros géneros como el retrato o el paisaje, (de este último se ha estudiado su carácter nacional en las obras de la segunda mitad de siglo, nada se sabe de las primeras décadas), podría aportar nuevas pistas a los investigadores.

El culto a la nación también se ha visto reflejado en las conmemoraciones y festividades. Para Jordi Roca, la recepción del universo simbólico es igual de importante que conocer quién y cómo lo creó $^{54}$; mientras que la segunda parte está más presente en los estudios históricos, la primera ha conseguido pocos seguidores. El interés por la receptividad del universo simbólico no se centra únicamente la multiplicidad de significados, sino también en los espacios de negociación y de actuación. En este sentido, Alejandro Quiroga propuso la división en tres espacios en los que actuaban los agentes nacionalizadores: público, semipúblico

en M. del C. Lacarra y C. Giménez (coord.), Historia y política a través de la escultura pública 1820-1920, Zaragoza, 2003, 41-62.

51. P. Bourdieu: Sobre el Estado... op. cit., 84.

52. J. Moreno Luzón y X. M. Núñez Seixas, Los colores de la patria: símbolos nacionales en la España contemporánea, Madrid, 2017; M. Nagore Ferrer, "Historia de un fracaso: el "himno nacional" en la España del siglo XIX”, Arbor: ciencia, pensamiento y cultura, 751, 2011, 827-845; J. Vernet, “Símbolos y fiestas nacionales en España", Teoría y realidad constitucional, 12-13, 2003, 99-122.

53. T. Pérez Vejo, España imaginada: historia de la invención de una nación, Barcelona, 2015, 498.

54. J. Roca Vernet, "Representar y celebrar el proceso de construcción nacional", en P. Gabriel Sirvent, J. Pomés y F. Fernández (eds.), "España res publica": nacionalización española e identidades en conflicto (siglos XIX $y$ XX), Granada, 2013, 3-10. 
y privado. El primero de ellos es donde las instituciones estatales están más presentes y son protagonistas. En segundo, la esfera semipública, es cuando actúan organismos privados dentro de un espacio público. Sus agentes pueden difundir la narrativa oficial, pero en espacios no institucionalizados. Por último, la esfera privada se reduce al ámbito familiar y de sociabilidad amistosa. En este espacio el individuo puede adquirir una identidad nacional a través de los «instrumentos de personalización de la nación» que pueden ser desde actividades de ocio hasta objetos personales que refuercen su identidad nacional ${ }^{55}$.

Centrándome en la primera de las esferas, un análisis a conciencia de estos escenarios permitirá observar el grado de nacionalización que produjeron las acciones institucionales; debe tenerse en cuenta la capacidad del Estado a nivel territorial y las diversas intencionalidades de sus actuaciones. ¿Puede considerarse una herramienta de nacionalización estatal la construcción ferroviaria? Tal y como se preguntaban Justo Beramendi y Antonio Rivera recientemente ${ }^{56}$, es posible que se contemplaran como un escenario plenamente económico, de negocios; sin embargo, pudieron influir en la construcción de una identidad de Estado debido al ceremonial generado a su alrededor ${ }^{57}$ : la inauguración de los caminos de hierro, su aparición en la prensa, e incluso las pinturas que inmortalizaron tales momentos.

Ha sido a raíz del «giro espacial» en la historiografía cuando los espacios públicos se han revalorizado en la creación de universos simbólicos. Bajo esta perspectiva, el espacio se comprende como algo en continua construcción e interpretación. Así, la decoración urbana en ceremonias o acontecimientos públicos se observa como una interesante vía para comprender las interacciones simbólicas entre el espacio urbano y nacional. En los últimos años, el análisis de los espacios públicos urbanos ha concluido en su uso como herramientas por parte de las instituciones gubernamentales para el control ciudadano. Las plazas, calles o parques pueden recibir diversas connotaciones -a partir de los nombres, de las instituciones ubicadas en ellas o la colocación de emblemas- con las que pueden adquirir un discurso político. Suelen configurar un mensaje proveniente de las esferas dominantes; sin embargo, las élites del poder no tienen la última palabra debido a que la recepción del discurso dependerá de los ciudadanos. Son auténticos espacios de negociación entre el discurso oficial y el social, en reconstrucción constante. Jordi Roca lo reflejaba en un estudio sobre varias plazas barcelonesas. Su análisis, se aproximaba a las transformaciones urbanísticas de las plazas del Palau, Sant Jaume y Reial, convertidas «en espacios centrales del revolucionario liberal, en las que se representaron prácticas, valores e ideas asociadas a la nación liberal $\aleph^{58}$. Cada uno de estos espacios ofrecieron distintas propuestas de nación: por un lado, se encontraba la

55. A. Quiroga, “La nacionalización en España...”, op. cit., 27.

56. J. Beramendi y A. Rivera, “La nacionalización española...”, op. cit., 18.

57. R. Ruzafa, "La/s nación/es en las inauguraciones de obras públicas en el norte de España (1830-1868)", en P. Gabriel Sirvent, J. Pomés y F. Fernández (eds.), "España res publica”: nacionalización española e identidades en conflicto (siglos XIX y XX), Granada, 2013, 25-36.

58. J. Roca Vernet, "Las plazas y la representación de la nación liberal. Barcelona 1820-1857”, en P. Gabriel Sirvent, J. Pomés y F. Fernández (eds.), "España res publica”: nacionalización española e identidades en conflicto (siglos XIX y XX), Granada, 2013, 12. 
narrativa simbólica construida desde las instituciones oficiales, y por otro, la apropiación de ese espacio por las fuerzas del liberalismo revolucionario que dotaron a esos espacios de un nuevo significado.

Observemos cada caso para ver las diversas herramientas con las que el discurso simbólico de estos espacios fue modificado: el cambio de nombre o la ornamentación con estatuas de personajes históricos son las prácticas más habituales para modificar el mensaje de espacios públicos. Eso ocurrió en la plaza del Palau, tradicionalmente considerada como el espacio de protesta contra la autoridad; para fortalecer su imagen cívica pasó a ser denominada la Plaza de la Constitución durante el Trienio Liberal. Años después, el capitán general de Barcelona, el conde de España, en un intento de cambiar la esencia revolucionaria de la plaza, quiso ubicar una estatua de Fernando VII en su centro; el mensaje del espacio público era modificado al resimbolizarlo con iconos de la monarquía nacional. En ocasiones el mensaje se modifica no por la ornamentación, sino por la ubicación de instituciones. El ejemplo de ello se observa en la plaza Sant Jaume, un espacio cuyo interés político se acrecentó al situar en su interior a la Diputación Provincial de Cataluña durante el Trienio Liberal. El edificio simbolizó «el centro de la política liberal en la ciudad (...) aunaba la representación de todos los cuerpos electos del régimen liberal» ${ }^{59}$; su proyectó llegó a su máximo esplendor con el cambio de nombre de la plaza por la de la Soberanía Nacional. Por último, el proyecto para la construcción de un gran espacio cívico en las Ramblas tuvo diversos planteamientos, desde la creación de una gran plaza dedicada a los Héroes Nacionales que con la llegada del moderantismo se transformó en un proyecto monumental para elogiar a Isabel II, a las artes y al comercio. El análisis del universo simbólico desarrollado en la urbe barcelonesa ha permitido observar la dinámica de las prácticas políticas y su utilización de los símbolos. Configura un claro ejemplo de las nuevas percepciones sobre los espacios de negociación urbanos que deberían ampliarse a otras zonas de la geografía española, y concretamente en el caso de Madrid, la capital del Estado.

La capacidad para emitir mensajes políticos e identitarios de los espacios urbanos madrileños quedó reflejado en el deseo de monumentalizar la capital durante el largo siglo XIX; la necesidad de crear una red de recuerdos - y esto puede unirse con los espacios de memoria de Pierre Nora- a partir de la colocación estratégica de un conjunto de efigies vinculadas a la narrativa nacional del Estado liberal, como si fuesen el santoral de la sociedad civil libe$\mathrm{ral}^{60}$. Esa monumentalización servía tanto para evocar héroes del pasado, como para generar recuerdos sobre símbolos de presente. No sólo hablamos de efigies colocadas en puntos estratégicos, sino de arquitecturas monumentalizadas como el Congreso de los Diputados, un edificio cuyo discurso iconográfico oficializaba una identidad nacional ${ }^{61}$.

\footnotetext{
59. J. Roca Vernet, “Las plazas y la representación de la nación liberal..., op. cict., 16.

60. C. Reyero, "Monumentalizar la capital..., op. cit., 42.

61. O. Luján, "Un palacio para todos: monumentalismo y políticas festivas en torno al Congreso de los Diputados en los inicios del liberalismo", en F. Luengo y F. Molina (coord.), Los caminos de la nación. Factores de nacionalización en la España contemporánea, Granada, 2016, 201-217.
} 
La villa madrileña era a mediados de siglo el centro político de la nación. A partir de 1849 las sedes estatales se distanciaron del área de influencia monárquica situada en el Palacio Real y cercanías. El eje de actuación política se movilizó hacia la puerta del Sol, sede del Ministerio de la Gobernación, conectado con la calle de Alcalá y la carrera de San Gerónimo, zonas en las que se ubicaron las Cortes y varias sedes ministeriales como Hacienda o Guerra. Un nuevo escenario político cobró vida en Madrid y, sin embargo, apenas tenemos estudios que profundicen en ello ${ }^{62}$. ¿Qué nos diría el estudio de su urbanismo desde un análisis similar al de Barcelona? Sería interesante aproximarse tanto a las transformaciones simbólicas de espacios públicos, como también a la creación de festividades o ceremonias ubicadas en espacios concretos de la vía urbana. Una primera aproximación en este sentido se encuentra en el estudio sobre la apertura y cierre del curso legislativo en el entorno del Palacio de las Cortes como un acontecimiento que pasó de ser político a abrirse a la sociedad y hacerla partícipe del mismo. ¿La población podría adquirir de ellas una cultura de Estado? Madrid era la capital del Estado y, por lo tanto, entre sus espacios se encontraban importantes escenarios de la política liberal en los que el pueblo podría ir adquiriendo una cultura de Estado. La particularidad de Madrid como capital añadiría la problemática de la recepción frente a las provincias; edificios como el Congreso de los Diputados generan espacios únicos imposibles de repetir, de ahí que en la aproximación a su universo simbólico se tenga en cuenta esta peculiaridad.

\section{Agentes}

La evolución lineal de la construcción del Estado ha provocado que los estudios promuevan una visión homogénea y, en ocasiones, reducida, de un proceso histórico que plantea grandes dificultades. Salirse de este análisis y romper con la linealidad permite acercarse a otros elementos de su construcción apenas tenidos en cuenta: los agentes históricos. Ellos son parte clave en la formación de los estados. Estas figuras combatieron en un escenario histórico desde sus intereses y desde su peculiar mirada sobre la política y su comprensión de lo que significaba el Estado. Un examen de sus discursos y redes de contacto nos permitiría aproximarnos al enmarañado ovillo social integrado en el organismo estatal ${ }^{63}$.

El balanceo constante de los agentes históricos entre espacios públicos y privados dificulta su estudio. Figuras como los gobernadores civiles se movían entre su pertenencia a un partido, su papel como representantes del Estado y sus redes de influencia ${ }^{64}$. En un principio, su presencia representaba la actuación estatal, sin embargo, como se ha observado en ocasiones y centrándome en el mundo artístico, sus actuaciones se alejaron de su representación institucional. La ambigüedad de sus acciones pudo contemplarse en los primeros años de

62. J. Pro, "El Estado y la administración pública en la ciudad (1833-1936)", en V. Pinto Crespo (coord.), Madrid. Atlas histórico de la ciudad, 1850-1939, Madrid, 2001, 270-299; M. Valenzuela, "Administración central y espacio urbano: aproximación a una Geografía Ministerial de Madrid", Boletín de la Real Sociedad Geográfica, 137-138, 2001-2002, 353-390.

63. S. Calatayud, J. Millán y M. C. Romeo, “Introducción: la formación del Estado..., op. cit., 11.

64. J. Álvarez Junco, Mater Dolorosa... op. cit., 542. 
la desamortización de Mendizábal. Por un lado, se crearon amplios debates entre los funcionarios de Hacienda y los académicos de Bellas Artes; desde Hacienda se debía tasar toda obra que no se considerase artística para incorporarla a las arcas estatales, pero la mayoría de estos funcionarios carecía del conocimiento para considerar si un bien era artístico o no, y en pro de mejorar la economía nacional tasaron y vendieron muchas obras valoradas como patrimonio nacional por los entendidos en la materia. Por otro lado, desde las comisiones de Gobernación, encargadas de hacer llegar los bienes artísticos desamortizados a Madrid, su precariedad laboral y un desconocimiento sobre el valor del patrimonio de la nación provocó que vendieran a manos privadas objetos artísticos que debían ser custodiados por el Estado $^{65}$. Discernir sus actuaciones como agente público o como acción personal son muy complejas, sobre todo en cuanto se observa la configuración de redes en la que los intereses públicos y privados se mezclan. Un análisis a conciencia de los miembros que conformaban las directivas museísticas, las comisiones de monumentos históricos o la formación de los jurados de las exposiciones de Bellas Artes permitiría aproximarnos a la red creada entre el mundo artístico y político a lo largo del siglo XIX. Esta idea ha sido propuesta en varias ocasiones desde que en 1987 Jesús Gutiérrez Burón dedicara su tesis doctoral al escrutinio de los certámenes nacionales de Bellas Artes en España; uno de los últimos estudios que retomaron el pensamiento lo encontramos en la obra de Jesusa Vega sobre la cultura visual en torno al imaginario nacional. El networking en esta ocasión, nos permitiría aproximarnos a los grupos a cargo del poder cultural y su interacción con otras esferas sociales ${ }^{66}$. Su percepción del Estado sería un interesante análisis, como ya lo han demostrado estudios dedicados a otros grupos del funcionariado como los ingenieros ${ }^{67}$, un sector ligado al mundo artístico. A través de las obras públicas, construcciones que difundían un mensaje de modernización estatal y del que quedan varios elementos que analizar. Sólo por mencionar una de las posibilidades, los trabajos de los fotógrafos Charles Clifford o Jean Laurent retratando las obras públicas y los edificios estatales han sido analizados desde diversas perspectivas -desde la propia historia de la imagen hasta la arquitectura urbana-; sin embargo, queda por conocer si su representación se anexionó a un imaginario de Estado, y en ese caso desde dónde se produjo y cómo se difundió.

Continuando con el análisis de colectivos relacionados institucionalmente con el Estado, se debería fomentar la investigación sobre las academias de Bellas Artes nacionales fuera de España: las sedes de Roma y París cuyos pensionados tenían el objetivo de fomentar el

65. J. Bello, Frailes, intendentes y políticos: los bienes nacionales, 1835-1850, Madrid, 1997.

66. J. Vega, Pasado y tradición. La construcción visual del imaginario español en el siglo XIX, Madrid, 2016, 54; J. Gutiérrez Burón, Exposiciones nacionales de pintura en España en el siglo XIX, Tesis doctoral, Madrid, 1987.

67. D. Martykánová, "Por los caminos del progreso. El universo ideológico de los ingenieros de caminos españoles a través de la "Revista de Obras Públicas" (1853-1899), Ayer, 68, 2007, 193-219; ÍD, "Las palabras de la ciencia útil: los conceptos en el discurso corporativo de los ingenieros de Estado”, en M. Pérez Ledesma (ed.), Lenguajes de la Modernidad en la Península Ibérica, Madrid, 2012, 389-4930; ÍD, "Las raíces de una tecnocracia: los ingenieros al servicio del Estado en España entre los 1780 y los 1830”, en D. RodríguezArias (coord.), Justicia ¿para todos? Perspectivas filosóficas, Madrid, 2016, 161-172. 
«genio nacional». En este colectivo artístico se entrecruzaban las narrativas nacionales que configuraban su identidad. Estas podían complementarse o no, generando una serie de contradicciones en la identidad del individuo. Los pensionados obtenían dinero del Estado para poder educarse en el extranjero; a cambio de ello, debían durante su estudio presentar composiciones bajo la directriz de la Academia, cuyo discurso nacional solía ser similar al oficial. Por otro lado, los artistas debían ensalzar el arte nacional frente al de otros países y procurar que su arte se identificase como español. Por último, debían lidiar con esas identidades externas, para configurar la suya propia desde su experiencia. Cuando los propios pensionados sufrían la crisis de un Estado que, en ocasiones, era incapaz de enviarles el dinero suficiente para mantenerse ¿Cómo difundir esa identidad nacional conformada por los grandes hitos y personajes del pasado? ¿Cómo trasladar esa imagen de grandiosidad de la nación española? Sobre estas cuestiones, el giro hacia el individuo aplicado al mundo artístico nos permitiría reflexionar sobre el papel de los artistas como generadores de narrativas nacionales desde su esfera privada y saber si ese discurso lo expondrían públicamente a través de sus obras.

En la aproximación al individuo, la esfera cotidiana entró en juego, advirtiendo nuevos modelos de nacionalización en los que la esfera privada, familiar y sus redes incidían en el proceso de identidad nacional de los individuos. Esto nos permitiría contemplar los diferentes grados de efectividad de la identidad oficial promovida por el Estado. ¿No vivir «en casa» consolida la narrativa oficial frente a la imagen creada por «el otro»? o, al contrario, ¿Al regresar al hogar se difunde una identidad influenciada por los imaginarios o estereotipos creados desde fuera? Para responder estas preguntas sería necesario analizar las autobiografías, biografías, epistolarios o memoras - fuentes rescatadas para el estudio histórico de los individuos $^{68}$ - de artistas, directores de museos o instituciones de arte, y de funcionarios vinculados a la sección de Bellas Artes y examinarlos más allá del punto de vista artístico.

\section{Primeras conclusiones}

En realidad, todavía estamos lejos de disponer de una historia cultural de la construcción del Estado. Los primeros pasos se han dado, pero los estudios son muy heterogéneos como para poder contemplar un panorama general. Este texto tenía el objetivo de presentar algunas posibles vías de estudio. Centrándonos en el mundo artístico y sus nexos con el aparato del Estado, se ha observado como, incluso teniendo en cuenta la línea de investigación más analizada, la construcción y difusión de una identidad nacional de arriba-abajo tiene muchas lagunas.

La renovación historiográfica y metodológica permite un cambio de perspectiva, genera nuevas preguntas de fuentes ya conocidas. La historia desde abajo ha abierto un abanico de posibilidades en el que el estudio de la sociabilidad, la cultura visual o la aproximación al individuo aportan nuevos datos en la investigación sobre la construcción del Estado. Aunque

68. F. Molina Aparicio, "La nación desde abajo. Nacionalización, individuo e identidad nacional", Ayer, 90, 2013, 39-63. 
Miscelánea | La arteria cultural del cuerpo estatal: el campo de las Bellas Artes en la construcción del Estado liberal español

es cierto que se han ampliado y mejorado las herramientas para lanzarse a este reto, no debe olvidarse la complejidad de este proceso histórico. Debe tenerse presente la temporalidad y el espacio del mismo, para evitar volver a caer en la formulación de grandes teorías que, cuando se aplican sobre prácticas concretas, no funcionan. 